\title{
Analysis of Factors Affecting the Housing Price in Different Cities of China and Macro Control Measures
}

\author{
Xue Ding, Ran Huang*, Xue Wang \\ Central China Normal University \\ School of Economics and Business Administration \\ Wuhan, China \\ 1037520512@qq.com
}

\begin{abstract}
In response to the rapidly rising of house prices in major cities across the country, the central and local governments at all levels have implemented multi-round home buying restriction policies since the end of 2016. Although the effectiveness of these policies is obvious at present, their impacts are lack of sustainability, and they are not conducive to the longterm development of the real estate market. Only by the in-depth analys is of the root causes of rising house prices in different types of cities and the macro-control policies of developing differentiation, can the real estate market in China achieves sustainable development. Based on the classical supply-demand theory, this paper studies the main influencing factors of house prices in the first, second and third tier cities by using gray relational analysis and principal component regression analysis. The results show: housing prices in the first-tier cities is a typical demand-pull housing prices; Second-tier cities housing prices is mainly affected by demand factors, but the influences of some supply factors are gradually increasing at the same time; Thirdtier cities housing prices is simultaneously affected by a number of the supply and demand factors, which is the most complex situation. Therefore, the macro-control policy and the construction of supporting mechanism must also reflect this diffe rence of cities.
\end{abstract}

Keywords-Housing Price; Difference of Housing Markets; Macro Control Measures;Supply;Demand

\section{INTRODUCTION}

Since 2015, China has implemented a new round of loose monetary policy, and the generalized money supply, the balance of RMB loans and the stock of social financing scale have all increased continuously. Stimulated by a series of loose policies, the real estate market has also entered a round of the period of rapid growth. However, from the second half of 2016, the popularity of the real estate market and the rising speed of house prices gradually broke away from the rational track. The price index of newly-built houses in 70 large and medium-sized cities rose rapidly year on year, reaching nearly $9 \%$ by September 2016, and the sales area index of commercial houses also reached nearly $40 \%$ year on year. The abnormal growth of the real estate market has attracted great attention from central and local governments at all levels, and the multiround real estate purchase restriction policy has been initiated. Up to June 2017, the price of newly-built commercial housing in first-tier cities and second-tier cities has decreased year-on-

Supported by the Fundamental Research Funds for the Central Universities(Approval Number: CCNU18Z YTS10) year for eight consecutive months and six consecutive months respectively.

Although the current restriction policy can effectively curb the rapid rise of house prices in hot cities, this administrative intervention method is only effective in the short term and lacks sustainability. The long-term sustainable control policy should not only fully consider the specific development situation of different types of cities, but also take into account the differences of real estate market characteristics and influencing factors of housing prices in different types of cities. From the microscopic point of view, the housing price is determined by the supply and demand in a certain economic environment as well as other commodity prices. Therefore, its price change is bound to be influenced by both supply and demand factors as well as the macroeconomic environment.

Some scholars consider the influence of monetary policies such as money supply, property tax, purchase restriction and loan restriction on house price from the perspective of demand. Liang Yunfang and Gao Tiemei(2007) combined the error correction model with panel data model, and made an empirical study on the relationship between housing price and credit, interest rate and economic fundamentals in 28 provinces (municipalities and autonomous regions) of China. It was found that credit scale had a larger influence on the east and west regions, but the middle region was smaller. Besides, the actual interest rate had a smaller influence on each region, and the actual influence was smaller ${ }^{[1]}$. Zhang Hong and Li Yang (2013) built a global vector autoregressive model, and through generalized impulse response analysis, we found that all regions showed similar response characteristics to money supply shocks. The growth of money supply would promote industrial output and real estate investment in all regions, but it would inhibit social consumption and house prices in the long term, and the central region was least affected ${ }^{[2]}$. On the basis of constructing short-term fluctuation model of house price in China, Zhang Hao et al (2015) adopted LSTVAR model and generalized the function of impulse response to make the empirical analysis and found that the increase of money supply could make the increase of house price rise up ${ }^{[3]}$.

Some scholars also explain the real estate price from the perspective of supply, starting from the investment cost of the house. For example, Huang Jing et al.(2009) analyzed the long- 
term equilibrium relationship between house price and land price through panel unit root test and panel cointegration test and also analyzed the coefficient of their long-term influence through DOLS and carried out granger causality test on house price and land price. The results show that in the long term, house price and land price are in the relationship of granger causality, but in the short term, house price shows the granger cause of land price, and land price does not show the granger cause of house price ${ }^{[4]}$. Kuang Weida (2012) established twosector general equilibrium models of real estate market and land market respectively, taking land price and house price as independent variables, introducing land transfer method as external variables, and using SYS-GMM estimation regression system to find that house price was mainly determined by supply and demand, while land price was mainly determined by house price ${ }^{[5]}$. Ju Fang et al. (2013) found that land transfer income in central China had a great stimulus to house price for a long time, but land transfer income in east and west China had a smaller stimulus to house price ${ }^{[6]}$. Zhou Yu (2014) established a general equilibrium model with single house price as dependent variable, land lever as independent variable, flat number of houses and white race as exogenous variables. After regression, it was found that land lever increased by one percentage point, and house price fluctuation increased by 0.16 percentage point ${ }^{[7]}$.

There are also scholars who studied from the perspective of supply-demand combination. Zou Zhizhuang and Niu Linlin (2010) estimated the demand and supply equation of urban housing in the framework of simultaneous equations from the standard theory of demand and supply of consumer durable goods, and obtained the estimated value of income and price elasticity of demand and price elasticity of supply ${ }^{[8]}$. Kuang Weida (2012) established a general equilibrium model of three departments of home buyers, developers and governments, and used 3SLS to conduct regression tests on the house price model, property tax model and land price model of 33 large and medium-sized cities in east, central and west China from 1996 to 2008. The results showed that improving property tax would reduce house price and raising the land price in the previous period would raise house price, but the regression coefficients of property tax and land price were relatively small, and the house price in eastern cities was mainly driven by demand, while that in central and western cities was mainly driven by cost ${ }^{[9]}$. Li Zhongfei and Zhang Hao(2015) established a local equilibrium model of maximizing the profits of real estate producers and consumers' utility. By using the data of 31 provinces (municipalities and autonomous regions) from 2002 to 2011, we made a time-phased regression analysis, and found that the rising of real estate prices in the sample range was the result of the combined effect of cost promotion and demand promotion. However, from 2002 to 2006, the rising of real estate prices had obvious cost-driven characteristics, while from 2009 to 2011, it had obvious demand-driven characteristics ${ }^{[10]}$. Yi $\operatorname{Bin}(2015)$ introduced real estate construction department and established HDSGE model on the basis of DSGE model. He used this model to conduct empirical research, and it was found that the effects of land supply and demand inhibition on house prices were comparable without considering the constraints of land supply ${ }^{[11]}$. Wang Yongru (2015) also found that the influence of demand on house prices was positive and the influence of supply on house prices was negative through regression analysis on the basis of the general equilibrium model of supply-demand. What's more, the degree of influence of demand on house prices was greater than that of supply ${ }^{[12]}$.

Of course, some scholars also believe that economic fundamentals such as educational resources, population and per capita income will affect housing demand and lead to house price fluctuations. For example, Shen Yue and Liu Gongyu (2004) made an empirical study on the relationship between housing price and economic fundamentals, and found that current information or historical information of economic fundamentals can partially explain the housing price level or change rate ${ }^{[13]}$. Zhang Hao, Li Zhongfei and others (2014) based on the phenomenon of educational capitalization in Beijing, Shanghai, Guangzhou, Shenzhen and other first-tier cities, took the transaction price of commercial housing and educational resources as the explanatory variable and chose the population size and GDP per capita as the control variable, and then conducted regression analysis on the data of 51 administrative regions from 2006 to 2012. As a result, it was found that the increase of high-quality educational resources has obvious impetus to the growth rate of house prices ${ }^{[14]}$.

Through looking through the existing resources and literatures, it is not difficult to find that more studies only focused on the influence of single factor on house price fluctuation, and a few literatures that comprehensively considered the two factors of supply and demand and also considered the main large and medium-sized cities in China as the analysis objects of the same type rather than distinguish the differences of influencing factors of different types of real estate markets. Housing is different from ordinary commodities, because it lacks cross-regional mobility of other commodities and is influenced by many factors such as the geographical location, economic development and population of the city and so on. China's real estate market is not a big market with balanced development, but an unbalanced market composed of many urban real estate markets with relative independence and different development. The development of these different types of urban real estate markets is quite different. Even in some first-tier cities in China like Beijing, Shanghai and Shenzhen, the trend and fluctuation of house prices also have their own characteristics. Therefore, the macro-control policies introduced by the government have different effects in different cities.

\section{TheOretical Analysis on Impacts of Housing Prices IN DIFFERENT CITIES}

\section{A. Impacts of Housing Demand}

As with all commodities, the demand for housing is mainly influenced by the price of the property and the real income of the residents. But as a special commodity, housing has both the nature of consumer and investment goods. Therefore, the housing demand includes both the rigid and investment demand. Generally, the house price is proportional to investment demand while inversely proportional to rigid demand. However, with the increase of residents' income, the rigid and investment demand will also increase. In conclusion, for rigid demand, the price effect is negative and the income 
effect is positive. For investment demand, the price effect is positive and the income effect is positive.

In addition, since the main demand for residential housing is residents, the population and educational setting also plays an important role in housing demand. The development of service and commerce industry is proportional to population size and density, the same goes for rigid and investment demand for housing. Furthermore, the high-level education will attract a large number of college students to study and work here, which will increase the rigid and investment demand for housing as well.

Based on the above analysis, the relationship between housing demand and these factors can be expressed as function (1)

Housing demand $=\mathrm{F}\{$ House Price $(\mathrm{HP})$, Population Size(Pop) , Average Wages (W), Educational Resources (Edu) (1)

Since the comprehensive economic strength is different among the first-tier, second-tier and the third-tier city, the housing demand varies as well. In general, the higher the housing price is, the larger the investment demand for housing will be. Therefore, the investment demand of the first-tier city is larger than that of the second-tier and the third-tier city. For the first-tier city, the economic and cultural development is high, and with the inflow of outsiders, the rigid and investment demand for housing has been very large. Compared with the first-tier city, the second-tier city, the economic and cultural development is not that high, so is the housing price. Thus the rigid demand for housing is relatively larger. For the third-tier city, the economic and cultural development is of low level, the house is of low price, the rigid demand for housing is relatively the largest.

\section{B. Impacts of Housing Supply}

From the perspective of supply, housing supply is significantly affected by the price. The higher the house price is, the more house will be supplied, vice versa. The land supply area, development investment and completed residential area are also the critical factors for housing supply. Since real estate development is the development on land, residential supply is closely related to land supply. The scarcity of land resources and high price on land lead to high development costs. Suppliers are less willing to purchase land, the residential development area and housing supply will reduce correspondingly. Suppliers increase investment, the real-estate boom, and the housing supply is relatively sufficient in this period. On the contrary, if suppliers reduce investment, the housing supply will be insufficient. That completed residential area supplies for new housing area directly affects the total supply of housing. The larger the completed residential area is, the larger the total housing supply is.

In conclusion, the relationship among housing supply and house price, land supply, completed residential area, development investment can be expressed as function (2)

House supply=F\{House Price(HP), Land Supply(L), Residential Area Completed(Com), Residential Development Investment(I)\} (2)
Nonetheless, due to the great differences in land resources, house price, etc., the housing supply among the first-tier, second-tier and the third-tier varies definitely.

\section{Residential equilibrium price analysis and test hypothesis}

From the analysis mentioned above, we can know that the final equilibrium house price $\mathrm{HP}$ will be influenced by population, income, educational resources, land supply area, residential completed area and residential investment. Increasing the population size and the income level and optimizing the educational resources will improve the rigid demand and investment demand of housing and promote the rise of equilibrium house price. High house price is accompanied by high profits, and suppliers are profitable, which will increase investment. However, as land resources are scarce, suppliers' investment is mainly used for competition of limited resources in order to increase costs and eventually transform into the growth of house price. Therefore, increasing investment will lead to further increase of equilibrium house price. The larger the land supply area is, the less competitively the suppliers get the land, and the lower the land costs, the lower the equilibrium house price will be. The larger the completed residential area is, the more residential supply will be and at the same time the lower the equilibrium house price will be. At present, the demand for housing in the first-tier cities is in short supply. After the completion of the housing, the supplier will not hoard property. Therefore, the larger the housing completion area in the first-tier cities is, the lower the equilibrium house price will be. Comparatively speaking, the housing price in the second and third tier cities is not high. After the completion of the housing, the supplier may hoard property, taking the opportunity to raise the housing price. Therefore, the growth of the housing completion area in the second and third tier cities may lead to the rise of the equilibrium housing price.

So which variables or variables dominate the formation of the final equilibrium price of different types of urban housing? According to the above analysis, we can sort out the following hypotheses to be verified.

First of all, the differences in economic development level, educational resources and land resources among the first, second and third tier cities are relatively large, which leads to the large differences in the factors that affect the fluctuation of house prices. Therefore, we can get the first hypothesis to be tested:

Hypothesis 1: there are significant differences between supply and demand factors on the housing price of first - tier, second-tier and third-tier cities.

Secondly, the education resources in the first-tier and second-tier cities are relatively good, and the rigid demand and investment demand are especially large. Besides, the wage income and population quantity greatly affect the rigid demand. Therefore, the demand elasticity in the first-tier and second-tier cities is relatively large. In addition, the land resources in the first-tier and second-tier cities are tight and the housing supply elasticity is relatively small, so the housing prices in the firsttier and second-tier cities should be mainly influenced by 
demand factors. Therefore, there is a second hypothesis to be tested:

Hypothesis 2: the house price of first-tier and second-tier cities is mainly influenced by demand factors.

Finally, due to the restrictions of economic development level, educational development level and total population in third-tier cities, the housing demand in third-tier cities is mainly rigid demand, and the changes of population and educational environment will affect the changes of demand, which will affect the house price in turn. And the land resources in third-tier cities are relatively loose. When the house price rises, the profit space of real estate developers expands and the real estate developers increase investment to further promote the rise of house price. Therefore, there is a third hypothesis to be tested:

Hypothesis 3: the house price in third-tier cities is influenced by supply and demand factors, which makes the situation more complicated.

\section{THE EMPIRICAL TEST OF INFLUENCING FACTORS OF HOUSING PRICES IN DIFFERENT TYPES OF CITIES}

\section{A. Data sources and statistical analysis}

\section{1) Data sources}

Different from the existing literature, it focuses on the firsttier cities such as Beijing, Shanghai and Shenzhen; this article selected 35 large and medium-sized cities with economic development level as the analysis sample. This is because housing prices in first-tier cities such as Beijing, Shanghai are much higher than those other cities, and their economic development also at the leading position in China. If only analysis the causes of price fluctuations in these cities, the relevant conclusions will lack universality. In order to further compare the causes of housing price fluctuations in various cities, 35 large and medium-sized cities are divided into first, second and third-tier cities according to the relevant national standards. In which four primary cities include Beijing, Shanghai, Guangzhou and Shenzhen; Nine second-tier cities, including Tianjin, Nanjing, Hangzhou, Jinan, Chongqing, Qingdao, Dalian, Ningbo and Xiamen; and 22 third-tier cities, including Shijiazhuang and Taiyuan. Hohhot, Shenyang, Changchun, Harbin, Hefei, Fuzhou, Nanchang, Zhengzhou, Wuhan, Changsha, Nanning, Haikou, Chengdu, Guiyang, Kunming, Xi'an, Lanzhou, Xining, Yinchuan, Urumqi.

According to the theoretical analysis of the second part, the empirical research will mainly use two kinds of variables when testing Hypothesis 1 - Hypothesis 3. The first category is the variable that affects the demand for housing, this article calls it the demand-type variable and includes: population size, income level, and education resources. The second category is that influences housing supply, It is also called the supply-type variable and includes: land supply, real estate development investment and residential supply (the definitions and units of each variable are shown in TABLE I). Since many of the variables can only collect data for 2006-2015 (such as the average wage of employees, the number of university students universities, etc.), this article will use 2006-2015 as the sample analysis interval (The above variables are all from the official

website of the National Bureau of Statistics of the People's Republic of China).

TABLE I. VARIABLE DEFINITIONS AND UNITS

\begin{tabular}{ccc}
\hline Name & Definition & Unit \\
\hline House Price & Residential Average Transaction & Yuan $/ \mathrm{m}^{2}$ \\
Population Size & Total Population in the Area & People \\
Income Level & Average Wages of Employees & Yuan/year \\
Educational Resources & Number of University Students & people \\
Land Supply & Land Purchase Area & $\mathrm{m}^{2}$ \\
Real Estate & Residential Development & Yuan \\
Development & Investment & $\mathrm{m}^{2}$ \\
Investment & Residential Area Completed &
\end{tabular}

2) The trend analysis of house price growth and fluctuation

Preliminary statistical analysis was made on the annual growth rate of residential price and residential price in the first, second and third tier cities respectively from 2006 to 2015, and the statistical results were shown in TABLE II. As can be seen from TABLE II, the house prices in the first, second and third tier cities are on the rise during this period, but the growth rate is different. The first-tier cities ranked the first with the growth rate of $14.15 \%$, while the second and third-tier cities maintained the growth with the average growth rate of about $10.5 \%$, which indicated that the property prices of main cities in China had generally increased rapidly during this period. The rapid growth of house prices in the first-tier cities was particularly significant, which was not only related to factors such as the steady rise of China's macro-economy and the rapid growth of personal income, but also related to policies such as the liberalization of the two-child policy, interest rate reduction and inventory removal. This also preliminarily verifies the content of hypothesis 1 .

In addition, there is a big difference in the house prices of the first, second and third-tier cities, with the average house price of the first-tier cities reaching 14,515.28 Yuan / $\mathrm{m}^{2}$, far exceeding that of the second-tier cities reaching 7,992.71 Yuan $/ \mathrm{m}^{2}$ and that of the third-tier cities reaching 4,878.71 Yuan / $\mathrm{m}^{2}$. Even from 2006 to 2015, the minimum house price of the first-tier cities is larger than the maximum house price of the third-tier cities. This shows that the development degree of real estate market in different regions is different mainly due to the obvious gap in social resources allocation, and a large number of superior resources are inclined to developed cities, which is pushing up the house prices of first and second-tier cities. This phenomenon also proves the judgment of hypothesis 2 to some extent.

Finally, the first-tier cities are the most profoundly influenced in the fluctuation range of house price and the fluctuation range of growth rate and then the second-tier cities are also affected and the third-tier cities have the smallest fluctuation, which indicates that there may be more investment and speculative demand in the first-tier cities. Once there is adverse news occurring, the growth rate of house price may 
fluctuate dramatically, and the real estate bubble may burst, which require the government to control the house price within

a reasonable range.

TABLE II. ST ATISTICAL ANALYSIS OF HOUSE PRICES AND GROWTH RATES

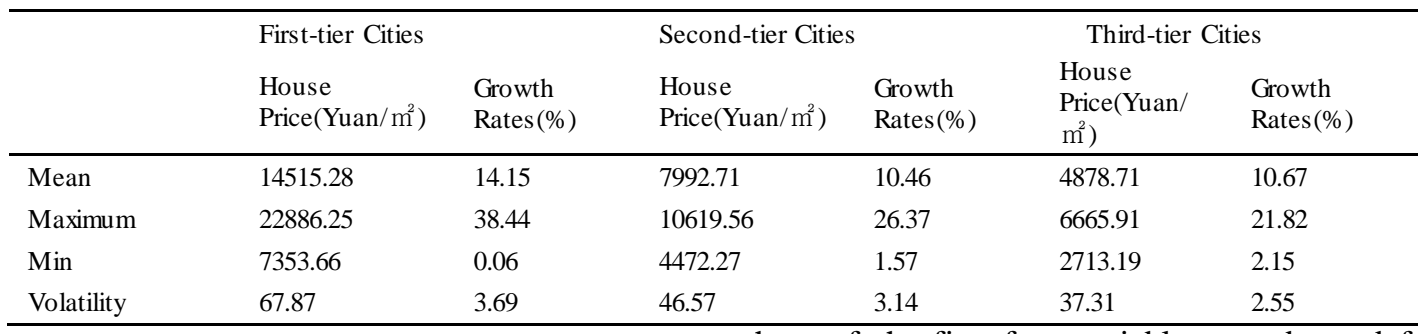

\section{B. The correlation test between the influencing factors and housing prices}

There are many factors that affect the house price. Through quantitative analysis of the correlation degree between each variable and house price, we can preliminarily ascertain the main variables that affect the rise of the house price. This paper selected the annual data so that the number of data is limited, and the gray correlation analysis method requires less sample size and it is also applicable to irregular data. Therefore, this paper will use this method to analyze the six selected indicators and house prices respectively, and get the correlation degree between each indicator and house prices. Next, the average value of gray correlation degree of each index in first, second and third line cities from 2006 to 2015 will also be calculated respectively ( see TABLE III ).

From TABLE III, it can be seen that the relationship between the first-tier cities and house prices is ranked in order of closeness, namely average wage of on-the-job workers, number of college students, and total population in the region, investment in residential development, land acquisition area and residential completed area. Therefore, as far as the correlation between factors and house price is concerned, demand variables are in the forefront, which further confirms the inference of hypothesis 2. Among them, the correlation between average wage of on-the-job workers and house price is the highest, which shows that family purchase and invest in first-tier cities are important factors to boost the house price. Secondly, the correlation between the total population and the number of students in institutions of higher learning and housing price is larger, which may be due to the greater rigid demand and better educational resources in the first-tier cities. The correlation between residential development investment and house price in re-supply variables is also high, which may be attributed to the high profits and high costs of residential market in first-tier cities pushing up investment in order to further push up the house price. Finally, because of the scarcity of land resources in the first-tier cities, the land acquisition area and the completed residential area are also related to the change of the house price.

The relationship between second-tier cities and house prices is ranked in close order as the number of college students, the investment in residential development, the total population in the region, the average wage of on-the-job workers, the completed residential area and the land acquisition area, which is also consistent with the inference of hypothesis 2 . Therefore, in the arrangement of correlation degree from big to small, three of the first four variables are demand factors. Among them, the relationship between the number of college students and housing price is the highest, which may be related to the rapid development of education level in second-tier cities in recent years. Secondly, the investment is related to housing price, which may be due to the fact that the real estate market in second-tier cities has not reached saturation, the profit space is larger, and high profits promote high investment so that the housing price is pushed up. Thirdly, the correlation between the total population and the average wage of on-the-job workers and housing price is larger, which is obviously due to the higher rigid demand of second-tier cities. Finally, the land purchase area and the completed residential area are related to the lag of residential supply and the shortage of land resources.

TABLE III. THE RESULT S OF GRAY CORRELATION ANALYSIS

\begin{tabular}{|c|c|c|c|c|c|c|}
\hline & pop & w & edu & i & l & com \\
\hline First-tier & 0.8886 & 0.897 & 0.8901 & 0.8565 & 0.5829 & 0.5096 \\
\hline $\begin{array}{l}\text { Second- } \\
\text { tier }\end{array}$ & 0.8643 & 0.8595 & 0.9139 & 0.8955 & 0.6207 & 0.8414 \\
\hline Third-tier & 0.8693 & 0.9014 & 0.903 & 0.9467 & 0.5784 & 0.8384 \\
\hline
\end{tabular}

The relationship between third-tier cities and house prices based on the close degree are listed as follows, namely the residential development investment, the number of college students, the average wage of on-the-job workers, the total population in the region, the completed residential area and the land acquisition area in turn. Among the third-tier cities, the highest degree of correlation with housing price is the investment in housing development, which should be attributed to the fact that the real estate market in the third-tier cities starts late, in which the competition is smaller, profits are larger and the investments are larger so that the housing price is further pushed up. Secondly, the number of college students, the average wage of on-the-job workers and the total population in the region are higher, which is also mainly due to the rigid demands of third-tier cities. Finally, since the land resources in the third-tier cities are relatively loose and the competition in the real estate market is relatively small, there is also a certain degree of correlation between both the completed residential area and the land purchase area and the house price. This analysis conclusion is consistent with the inference of hypothesis 3 . 


\section{Comparative analysis of influencing factors of the housing price in first, second and third-tier cities}

Linear regression analysis is a widely used quantitative analysis method when analyzing the related influencing factors of house price fluctuation. However, this method not only requires a high number of samples, but also assumes strict conditions. For example, there cannot be a high degree of correlation among explanatory variables, and samples must conform to a specific probability distribution and so on. However, the hypothesis of principal component regression analysis is relatively loose, which can overcome the estimation errors caused by the high correlation between explanatory variables and the small sample size. Therefore, the following analysis in this paper adopts the method of the analysis of principal component regression.

1) Empirical analysis of housing price in first-tier cities

TABLE IV shows the eigenvalues and variances of principal component analysis of house prices in first-tier cities. According to the principle that the eigenvalue is greater than 1 , the principal components are extracted, and two principal factors are extracted. The variance contribution rate of the first principal factor is $72.009 \%$, and the second is $19.468 \%$. These two principal factors together can reflect $91.476 \%$ of information of the original six indicators, so the principal component model can be established.

TABLE IV. TOT AL VARIANCE EXPLAINED BY FIRST-TIER CITIES

\begin{tabular}{|c|c|c|c|c|c|c|c|c|c|}
\hline \multirow{2}{*}{ Factor } & \multicolumn{3}{|c|}{ Initial Eigenvalue Value } & \multicolumn{3}{|c|}{ Factor Loadings } & \multicolumn{3}{|c|}{ Rotate } \\
\hline & Eigenvalue & Proportion & Cumulative & Eigenvalue & Proportion & Cumulative & Eigenvalue & Proportion & Cumulative \\
\hline 1 & 4.32 & 72.01 & 72.01 & 4.32 & 72.01 & 72.01 & 4.29 & 71.56 & 71.56 \\
\hline 2 & 1.17 & 19.47 & 91.48 & 1.17 & 19.47 & 91.48 & 1.20 & 19.92 & 91.48 \\
\hline 3 & 0.44 & 7.38 & 98.85 & & & & & & \\
\hline 4 & 0.03 & 0.56 & 99.41 & & & & & & \\
\hline 5 & 0.03 & 0.49 & 99.90 & & & & & & \\
\hline 6 & 0.01 & 0.10 & 100 & & & & & & \\
\hline
\end{tabular}

TABLE V. FIRST-TIER CITIES' FACTOR MATRIX

\begin{tabular}{lll}
\hline & Factor $\mathbf{1}$ & Factor $\mathbf{2}$ \\
\hline Pop & 0.986 & -0.063 \\
W & 0.969 & -0.14 \\
Edu & 0.984 & 0.051 \\
I & 0.944 & -0.21 \\
L & 0.014 & 0.948 \\
Com & -0.742 & -0.447 \\
\hline
\end{tabular}

TABLE $\mathrm{V}$ is a factor matrix table of principal component analysis in first-tier cities. The principal component 1 is denoted by F1, and the principal component 2 is denoted by F2. Then we can get the coefficients corresponding to each index in the two principal components by dividing the data in the component matrix table by the square root of the corresponding eigenvalue of the principal component and get the principal component expression as follows:

$F 1=0.4743 \hat{p o p}+0.4662 \hat{w}+0.4734 \hat{e d u}+0.454 \hat{\imath}+0.0067 \hat{l}-0.3570 \widehat{\operatorname{com}}$

$F 2=-0.0538 \widehat{p o p}-0.1295 \hat{w}+0.0472 \widehat{e d u}-0.1943 \hat{\imath}+0.8772 \hat{l}-0.4136 \widehat{c o m}$

Then three variables are used to conduct regression analysis and house price HP and the regression equations of F1 and F2 are respectively established. Firstly, the regression model is checked. As can be seen from TABLE VI, the $\mathrm{R}$ of the regression test of this model is 0.95 , which indicates that the fitting effect of this model is good. F1 has a significant influence on house price $(\mathrm{p}<0.05)$. If the $\mathrm{t}$ - value test of F2 fails, the F2 model is rejected, and the constant term test fails, then the regression equation established by this model is as follows:

$$
\widehat{h p} 1=0.97 F 1
$$

The regression formula of the original variable obtained after deformation is as follows:

$H P 1=-26.68+3.77 p o p+0.51 w+1.73 e d u+0.45 i-0.01 l-0.72 \mathrm{com}(6)$

Coefficients of the respective variables represent the degree of their influence on house prices. The regression analysis of the house price in the first-tier cities shows that the biggest influence on the house price is the total population, and the second largest one is the number of college students. Both of them are demand factors. Meanwhile, the absolute value of the coefficient is much larger than other factors. Obviously, although supply factors also have some influence on the house price in the first-tier cities, the house price in the first-tier cities is dominated by demand factors, and this test result supports hypothesis 1 and hypothesis 2 .

TABLE VI. FIRST-TIER CITIES’ PRICE REGRESSION MODEL TEST

\begin{tabular}{|c|c|c|c|c|c|c|c|c|c|}
\hline & \multirow[b]{2}{*}{$\mathrm{R}$} & \multirow[b]{2}{*}{$\mathrm{R}^{\wedge} 2$} & \multirow{2}{*}{$\begin{array}{l}\text { Adjust } \\
\mathrm{R}^{\wedge} 2\end{array}$} & \multirow{2}{*}{$\begin{array}{l}\text { Standard } \\
\text { Estimate } \\
\text { deviation }\end{array}$} & \multicolumn{2}{|c|}{ Non-standardized coefficient } & \multirow{2}{*}{$\begin{array}{c}\text { Standard } \\
\text { coefficient }\end{array}$} & \multirow[b]{2}{*}{$\mathrm{t}$} & \multirow[b]{2}{*}{ Sig. } \\
\hline & & & & & $\beta$ & $\begin{array}{l}\text { Estimate } \\
\text { deviation }\end{array}$ & & & \\
\hline constant & 1 & 1 & 0.93 & 0.26 & & & & & \\
\hline constant & & & & & 0 & 0.08 & & 0 & 1 \\
\hline F1 & & & & & 0.97 & 0.09 & 0.97 & 11.3 & 0 \\
\hline $\mathrm{F} 2$ & & & & & -0.1 & 0.09 & -0.1 & -0.5 & 0.61 \\
\hline
\end{tabular}

Housing prices in four of the first-tier cities are high, and the growth rate is fast at the same time. From 2006 to 2015, housing prices in Beijing rose by $202 \%$, in Shanghai by $205 \%$, in Guangzhou by $129 \%$, and in Shenzhen by $280 \%$. The average wage of on-the-job workers in the first-tier cities has also increased dramatically. In 2015, the wage of on-the-job workers in Beijing was 113,073 yuan / year, and the growth rate from 2006 to 2015 was $182 \%$; In Shanghai, it was 109,279 yuan / year, with a growth rate of $165 \%$; In Guangzhou, it was 81171 yuan / month, with a growth rate of 121 \%; In Shenzhen, it was 81034 yuan / month, with a growth rate of $131 \%$. There are many permanent residents in the firsttier cities, but the registered population is relatively small. In 2015, the number of permanent residents in Beijing reached 21.75 million, the registered population reached 13.452 million; the resident population in Shanghai reached 24.127 million and the registered population reached 14.497 million; the registered population in Guangzhou reached 13.511 million and the registered population in Shenzhen reached 11.338 million, and the registered population was only 3.549 million. The high income and large population of workers in the first-tier cities, especially the large number of non-resident population, directly lead to the large rigid demand of housing, the higher house price, which will improve the investment demand further and also improve the house price. 


\author{
2) Empirical analysis of housing price in second-tier \\ cities $^{1}$ \\ Using principal component regression analysis to find a \\ principal factor:
}

$F 1=0.4294 \hat{p o p}+0.4294 \hat{w}+0.4246 \hat{e} \hat{d} u+0.4246 \hat{\imath}-0.3139 \hat{l}+0.4151 \widehat{c o n}$

Then two variables are used to conduct regression analysis and house price $\mathrm{HP}$ and the regression equations of F1 is established:

$$
\widehat{h p} 2=0.948 F 1
$$

The regression formula of the original variable obtained after deformation is as follows:

$H P 2=-43.98+6.198 p o p+0.3584 w+1.0198 d u+0.2283 i-0.4967 l+0.6697$ con

The regression analysis of the house price in the second-tier cities shows that the biggest influence on the house price is the total population, and the numbers of college students, both of them are demand factors. Then the third and fourth are Com and l, both of them are supply factors. It can be seen that although housing prices in second-tier cities are jointly affected by demand and supply, demand factors have a greater impact. This conclusion supports Hypothesis 1 and Hypothesis 2.

From 2006 to 2015, the biggest growth rate of house prices in second-tier cities is Xiamen, which has reached $187 \%$. There are many universities in Xiamen and the growth rate of the number of university students has reached $80 \%$ in the past ten years. Xiamen has a small area and limited land resources, compared with 2006; the area of land purchased in 2015 was reduced by $42 \%$. Xiamen's superior educational resources and high income make the demand for residential buildings higher, suppliers are profitable, and investment will be increased. However, Xiamen's limited land resources will push up the cost of land acquisition and further push up prices.

3) Empirical analysis of housing price in third-tier cities

Using principal component regression analysis to find a principal factor:

$$
F 1=0.4252 \hat{p o p}+0.4309 \hat{w}+0.4283 \widehat{e d u}+0.43 \hat{\imath}-0.3235 \hat{l}+0.4004 \widehat{\operatorname{con} \gamma}
$$

The regression equation was obtained with the regression equation of price HP3 for F1.

$$
\widehat{h p} 3=0.98 F 1
$$

The regression formula of the original variable obtained after deformation is as follows:

$H P 3=-22.9224+3.4411 p o p+0.3611 w+0.8454 d u+0.2375 i-0.4178 l+0.5693$ com

It shows that the biggest influence on the house price is the total population, and the number of university students, Both of them are demand factors, However, the housing supply area and land acquisition area ranked third and fourth place have a greater influence on house price, and the absolute value of the coefficient is not significantly different from the demand factor. Therefore, the housing prices in third-tier cities are affected by

\footnotetext{
${ }^{1}$ Due to space limitation, the principal component regression results of second - and third-tier cities are not shown.
}

the demand and supply of multiple factors, and the situation is more complex, which supports the conclusion of hypothesis 3 .

Third-tier cities housing price have been relatively slow and their prices are relatively low. Third-tier cities cost drives prices a bit more obvious and in Changchun for example, Its land resources are relatively loose, and the development rate of the real estate market is lower than that of the first-tier and second-tier cities, real estate supplier of land purchase area and residential area is relatively higher, From 2006 to 2015, the growth rate of land purchase in Changchun reached 55\%, and the completed residential area reached $56 \%$.

\section{CONCLUSIONS AND POLICY RECOMMENDATIONS}

In order to cope with the rapid increase of house prices in major cities in China, central and local governments at all levels implemented multiple rounds of purchase restriction policy at the end of 2016. As far as regulatory effect is concerned, a series of current purchase restrictions have indeed effectively restrained the rapid rise of house prices in hot cities to some extent. However, administrative intervention means often can only achieve short-term results and lack of sustainability. Since housing is different from common commodities and does not have cross-regional mobility, which is subject to regional influencing factors such as geographical location, economic development level, population, educational resources and so on. Hence, the development degree and influencing factors of real estate market in different cities are quite different. Therefore, in order to promote the sustainable development of China's real estate market, it is necessary to deeply analyze the differences of influencing factors of house price rise in different cities, and accordingly implement differentiated macro-control policies and construct long-term control mechanisms. Based on this, from the perspective of supply-demand combination, this paper firstly makes a theoretical analysis of the causes of house price fluctuation in the first, second and third tier cities in China, and then puts forward the hypothesis to be tested that reflects the differences of influencing factors in different types of cities. Then, empirical data is used to test and analyze these hypotheses one by one, and finally the following conclusions and policy recommendations will be gained:

(1) The supply and demand factors have significant differences on the housing price of the first, second and thirdtier cities in China. House prices in first-tier and second-tier cities are mainly influenced by demand factors, while house prices in third-tier cities are mainly influenced by supply and demand factors, which make the situation more complex.

(2) The house price in the first-tier cities is a typical demand-driven model. The house price fluctuation in the firsttier cities is mainly influenced by the total population, the number of college students and the wages of on-the-job workers, but the supply factors have little influence. This is due to the political, economic and cultural position of the first-tier cities, which attract a large number of population inflows, and the resulting rigid demand supports high house prices. Secondly, it is due to the superiority of the educational environment in the first-tier cities. The degree of economic development is higher, and the demand of residential investment is higher. Finally, as there is a large number of 
overseas hot money inflows in the first-tier cities, the real estate market will have higher speculative demand because of its high rate of return. According to the characteristics of the first-tier cities, we should start from two aspects to control the excessive growth of housing price. Firstly, speeding up the construction of affordable housing to ensure the basic residential demand of residents and to solve the problem of excessive rigid demand and fundamentally relieve the high housing price. Secondly, we will continue to implement the purchase restriction policy to reduce investment demand and curb speculative demand.

(3) The house price in second-tier cities is mainly influenced by demand factors, but the influence of supply factors is also gradually increasing. The empirical study in this paper shows that the housing price fluctuation in second-tier cities is most influenced by the total population and the number of college students, followed by the completed residential area and land supply area. Therefore, regulating house prices in second-tier cities should not only suppress demand but also increase supply. On one hand, vigorously developing the housing rental market and reducing the housing demand. On the other hand, second-tier cities should optimize the land supply pattern while expanding the land supply in order to reduce land costs and house prices.

(4) The third-tier cities are mainly influenced by demand and supply. From the empirical study of this article, we can know that the third-tier cities are influenced by many factors, such as the total population, the number of college students, the completed residential area, and the land supply area and so on, and the difference of influence degree is small. Then, as for the third-tier cities, on one hand, we should reduce the investment in residential market, suspend the land supply and avoid the further expansion of new residential supply. On the other hand, we will improve the rigid demand by reducing the price and promoting sales, and at the same time optimize the educational environment of third-tier cities, actively promote the economic and cultural construction of third-tier cities, and improve their investment demand.

\section{REFERENCES}

[1] Liang Yunfang, Gao Tiemei. An Empirical Analysis of Regional Differences of Real Estate Price Fluctuations in China. Economic Research Journal. Beijing, pp.133-142, August 2007.(In Chinese)

[2] Zhang Hong, Li Yang. Research on Regional Differences of Conductive Effects of Real Estate Market on Monetary Policy--An Empirical Analysis Based on GVAR Model. Journal of Financial Research. Beijing, pp.114-128,February 2013. (In Chinese)

[3] Zhang Hao, Li Zhongfei, Deng Baijun. The Policy Uncertainty, Macro Impact and House Price Fluctuation: Based on the LSTVAR Model. Journal of Financial Research. Beijing, pp.33-44, October 2015. (In Chinese)

[4] Huang Jing, Tu Meizeng. An Empirical Analysis on the Relationship of Chinese Cities' Housing Prices and Land Price: Based on Non-Stationary Panel Econometrics Methods. Statistical Research. Beijing, pp.13-19, July2009. (In Chinese)

[5] Kuang Weida. Land Transfer Methods, Land Prices and House Prices.Journal of Financial Research. Beijing, pp.56-68, August 2012. (InChinese)

[6] Ju Fang, Lin Huiye, Zhou Jianjun. A Study on the Effect on Real Estate Price from Land Transfer Revenues and Local Fiscal Expenditure in Different Provinces of China. The Theory and Practice of Finance and Economics. Hunan, pp. 77-81, January,2013. (In Chinese)

[7] Zhou Yu. Land Leverage Impact on U.S. Experience in Price Fluctuations in Urban Housing. Construction Economy. Beijing, pp.74-76, May 2014.(In Chinese)

[8] Zou Zhizhuang, Niu Linlin. Demand and Supply of Urban Residential Housing in China. Journal of Financial Research. Beijing, pp.110,January 2010. (In Chinese)

[9] Kuang Weida. Property Tax, Land Prices and House Prices. China Soft Science. Beijing, pp.28-30, April 2012. (In Chinese)

[10] Li Zhongfei, Zhang Hao. Cost-Push or Demand-Pull: What Is Driving the Housing Prices in China?. Chinese Journal of Management Science. Beijing, pp. 144-149, May 2015. (In Chinese)

[11] Yi Bin. Housing-Demand Suppression or Land-Supply: A Comparison of Real Estate Control Policy. Journal of Finance and Econo mics. Shanghai, pp.66-70, February 2015. (In Chinese)

[12] Wang Yongru. The Influence of Real Estate Market Supply and Demand on Housing Prices. Statistics \& Decision. Hubei, pp.150-153, December 2015. (In Chinese)

[13] Shen Yue, Lin Hongyu. Housing Prices and Economic Fundamentals: An Cross City Analysis of China for 1995-2002. Economic Research Journal. Beijing, pp.77-85, June 2004. (In Chinese)

[14] Zhang Hao, Li Zhongfei, Deng Baijun. Educational Resource Allocation Mechanism and Housing Price: An Empirical Analysis of Education Capitalization in China [J]. Journal of Financial Research. Beijing, pp.193-204, May 2014. (In Chinese). 